\title{
EFFECT OF DIFFERENT CRYOPROTECTIVE AGENTS ON SKIM MILK AND DIMITROPOULUS EXTENDER FOR STALLION SEMEN CRYOPRESERVATION
}

\author{
R. I. Arifiantini, B. Purwantara, T.L. Yusuf and D. Sajuthi \\ Department of Clinic, Reproduction and Pathology, Faculty of Veterinary Medicine \\ Bogor Agricultural University, Darmaga, Bogor 16680 - Indonesia \\ CorrespondingE-mail:Iis_arifiantini@telkom.net
}

Received November 17, 2009 ; Accepted February 27, 2010

\begin{abstract}
Cryoprotective agents (CPAs) protect sperm during cryopreservation. The objective of this study was to assess different CPAs on stallion semen cryopreservation. Skim milk (SM) and Dimitropoulos (DV) were the extenders used in this study; each was added by glycerol (Gly), combination of ethylene glycol-glycerol (EG+Gly) or dimethilformamide (DMF). Each semen sample was evaluated and divided equally into six tubes; semen in the three tubes was diluted 1:1 with (SM), while in the remaining tubes the semen was diluted 1:1 by DV. After being diluted, all tubes were centrifuged at $1006 \mathrm{xg}$ for 10 minutes. The supernatan discarded, the pellet was rediluted by SM trehalosa or DV trehalose, and added by G, EG+Gly, or DMF to reach the final sperm concentration of $200 \times 10^{6} / \mathrm{ml}$. The extended semen was individually packed in $0.3 \mathrm{ml}$ minitube, equilibrated at $4^{\circ} \mathrm{C}$ for 2 hours, frozen in liquid nitrogen vapor for 10 minutes, and then was stored in liquid nitrogen container at $-196{ }^{\circ} \mathrm{C}$. After 24 hours, the semen was thawed at $37{ }^{\circ} \mathrm{C}$ for 30 second. There were no significantly different $(p>0.05)$ on the percentages of motile and viable sperm in SMT (21.7\% and 43.4\%, respectively) compared with those extended with DV T extender (26.9\% and 50.8\%, respectively). DMF demonstrated better results as CPA compared to the others; and DVTDMF combination had the best protection during cryopreservation in this study.

Keywords: cryopreservation, stallion sperm, sugar, cryoprotective agents
\end{abstract}

\section{INTRODUCTION}

Stallion semen has low freezing capability; only $24 \%-40 \%$ stallion sperm survived after freezing (Linfor et al., 2002; Vidament et al., 2002; Alvarenga et al., 2004). Drastic changes in temperature during chilling, freezing, or thawing of semen, and changes in osmotic pressure during preservation with cryoprotectants cause significant damages on the sperm plasma membrane.

Cryoprotectant is a substance required in semen freezing. The ideal cryoprotectants have low molecular weight and low toxicity, and should be easily diluted in distilled water (Alvarenga et al., 2005). Cryoprotectants can be classified based on the basic ingredient; alcohol group (ethylene glycol and alcohol) and amides (methylformamide and dimethylformamide). Glycerol penetrates bull sperm within 3-4 minutes (Berndtson and Foote, 1972); it is not surprising that glycerol is the most commonly used cryoprotectant to freeze bull, ram, buck, and stallion semens.

The cryoprotective capacity of a compound is dependent upon both the number of lone-pair electrons the compound contains, the spherical symmetry of the lone-pair electrons, and the solubility of the compound in water (Nash, 1996). The toxicity of compounds to cells depends upon both its chemical toxicity to cells (Nash, 1996), and its osmotic toxicity (Gao et al., 1995), which is induced when the membrane permeability of a penetrating cryoprotectant is much slower than water (Gao et al., 1995).

The first report on amides as cryoprotectants in the freezing of stallion semen was in the year of 2000; since then, studies on amides, such as methylformamide (MF) and dimethylformamide (DMF) have been popular, although the mechanism of their protection to stallion sperm during freezing was poorly understood.

Sugars such as glucose and fructose are the major energy source, while high molecular weight-sugars serve as extracellular cryoprotectants. Sugars are often used as non- 
Tabel 1. Composition of Extender

\begin{tabular}{|c|c|c|c|c|}
\hline Extender & \multirow{2}{*}{ amount } & G & EG & DMF \\
\hline Skim & & \multicolumn{3}{|c|}{$(\%)$} \\
\hline Skim milk powder (g) & 2.4 & 5 & $3 \& 3$ & 5 \\
\hline Glucose (g) & 4 & & & \\
\hline Mili-Q water (ml) & 100 & & & \\
\hline Trehalosa (mM) & 50 & & & \\
\hline Streptomycin (mg) & 100 & & & \\
\hline Penicillin (IU) & 100000 & & & \\
\hline Osmotic pressure (mOsm/kg) & & 1089 & 1317 & 1234 \\
\hline \multicolumn{5}{|l|}{ DV } \\
\hline Lactose $11 \%(\mathrm{w} / \mathrm{v})(\mathrm{ml})$ & 50 & 5 & $3 \& 3$ & 5 \\
\hline Glucose - EDTA (ml) & 25 & & & \\
\hline Trehalose (mM) & 50 & & & \\
\hline Eggyolk (ml) & 20 & & & \\
\hline Equex STM (ml) & 0.5 & & & \\
\hline Streptomycin (mg) & 100 & 100 & 100 & 100 \\
\hline Penicillin (IU) & 100000 & 100000 & 100000 & 100000 \\
\hline Osmotic pressurev(mOsm/kg) & & 1380 & 1392 & 1158 \\
\hline
\end{tabular}

penetrating cryoprotectants in combination with penetrating cryoprotectants. Differences in the cryoprotectant abilities of different sugars have been demonstrated for bulls and rams. Trehalose and sucrose, demonstrated a significant interaction between cooling rates and the presence of sugars (Woelders et al., 1997). Trehalose is a high molecular weight-sugar, acts as an extracellular cryoprotectant (Rudolph and Crowe, 1985). Supplementation of trehalose and EDTA in ram semen demonstrated a better preservation to the percentage of motile sperm during cryopreservation than fructose (Aisen et al., 2000).

However, equine spermatozoa cannot survive freezing without a cryoprotectant. Therefore, there is a need to evaluate other cryoprotectants that might be less toxic than glycerol to stallion spermatozoa. This study aimed to evaluate the quality of stallion frozen semen using different cryoprotective agents on skim milk and Dimitropoulus extender.

\section{MATERIALS AND METHODS}

Three stallions used in the study belong to Athena Stable, Cinere-Depok; a fourth generation (F4) Throughbred, an American pinto, and a warmblood Swedish. All stallions were 5-8 years old, healthy, and had demonstrated the best quality on the daily sperm evaluation.

An less state all chemical were obtained from Merck,KgaA, Darmstadt Germany. Two types of centrifugation extender used in this study were skim milk-glucose (Kenney et al., 1975) and Dimitropoulos (DV) (Ijaz and Durchame, 1995). Skim milk-glucose extender was composed of 2.4 g skim milk (Tropicana slim, plain) and $4 \mathrm{~g}$ glucose, which were diluted in $100 \mathrm{ml}$ Milli-Q water. The mixture was heated for 10 minutes at 92-95 ${ }^{\circ} \mathrm{C}$, allowed to cool, and then it was filtered, added by $100 \mathrm{mg}$ Streptomycin (Meiji, Japan) and 100,000 IU Penicillin (Meiji, Japan). DV extender consisted of two parts, solution A and solution B. Solution A was composed of $12 \mathrm{~g}$ glucose and 12 $\mathrm{g}$ fructose, which were diluted in $600 \mathrm{ml}$ Milli-Q water; the mixture was heated for 15 minutes at $95^{\circ} \mathrm{C}$, allowed to cool, and then it was stored in the refrigerator for a maximum of a week. Solution B was composed of sodium citrate, $9.4 \mathrm{~g}$ glycin and $3.5 \mathrm{~g}$ sulfanilamide, which were diluted in $1000 \mathrm{ml}$ Milli-Q water; the mixture was heated until it reached $100^{\circ} \mathrm{C}$, allowed to cool, and then it was stored at ambient temperature for a maximum of a week. DV centrifugation extender was made of $30 \%$ solution A, $50 \%$ 
solution B, and $20 \%$ egg yolk; the mixture was centrifuged, and then 1000 IU Penicillin and $1 \mathrm{mg}$ Streptomycin were added per milliliter supernatant.

Skim milk-based frozen semen extender was supplemented by $50 \mathrm{mM}$ trehalose. DV frozen semen extender was composed of $50 \mathrm{ml} 11 \%$ $(\mathrm{w} / \mathrm{v})$ lactose, $25 \mathrm{ml}$ glucose-EDTA solution (60 g glucose, $3.70 \mathrm{~g}$ sodium citrate, $1.20 \mathrm{~g} \mathrm{NaHCO} 3$, diluted in $1000 \mathrm{ml}$ Milli-Q water), $20 \mathrm{ml} \mathrm{egg}$ yolk, $0.5 \mathrm{ml}$ equex (orvus es paste, Novo, USA), supplemented by $50 \mathrm{mM}$ trehalose. Each extender

Tabel 2. Mean ( \pm S.E.M.) Percentage of Progressive Motile and Viable Sperm of Stallion Frozen Semen Diluted in Skim and DV with Different Cryoprotective Agent

\begin{tabular}{|c|c|c|c|c|c|c|}
\hline \multirow[t]{2}{*}{ Freezing step } & \multicolumn{3}{|c|}{ Skim trehalosa } & \multicolumn{3}{|c|}{ DV trehalosa } \\
\hline & G & EG & DMF & $\mathrm{G}$ & EG & DMF \\
\hline \multicolumn{7}{|l|}{ Raw semen } \\
\hline Motile (\%) & $67.5 \pm 7.2^{\mathrm{a}}$ & $67.5 \pm 7.2^{\text {a }}$ & $67.5 \pm 7.2^{\mathrm{a}}$ & $67.5 \pm 7.2^{\mathrm{a}}$ & $67.5 \pm 7.2^{\mathrm{a}}$ & $67.5 \pm 7.2^{\mathrm{a}}$ \\
\hline Viable $(\%)$ & $78.4 \pm 7.7^{\mathrm{a}}$ & $78.4 \pm 7.7$ a & $78.4 \pm 7.7^{\mathrm{a}}$ & $78.4 \pm 7.7^{\mathrm{a}}$ & $78.4 \pm 7.7^{\mathrm{a}}$ & $78.4 \pm 7.7^{\mathrm{a}}$ \\
\hline \multicolumn{7}{|c|}{ After equilibration } \\
\hline Motile (\%) & $56.0 \pm 9.1^{\mathrm{b}}$ & $52.0 \pm 9.2^{\mathrm{b}}$ & $57.5 \pm 8.9^{b}$ & $55.5 \pm 9.9^{b}$ & $52.0 \pm 11.1^{b}$ & $57.0 \pm 9.8^{\mathrm{b}}$ \\
\hline Viable $(\%)$ & $68.5 \pm 7.0^{\mathrm{b}}$ & $65.9 \pm 8.6^{b}$ & $68.3 \pm 7.2^{b}$ & $71.2 \pm 8.7 \mathrm{ab}$ & $72.2 \pm 7.1^{\mathrm{ab}}$ & $71.3 \pm 7.6 \mathrm{ab}$ \\
\hline \multicolumn{7}{|l|}{ After thawing } \\
\hline Motile (\%) & $23.7 \pm 6.4^{\mathrm{d}}$ & $12.8 \pm 5.0^{\mathrm{e}}$ & $28.5 \pm 5.6^{d}$ & $27.8 \pm 5.5^{\mathrm{d}}$ & $16.7 \pm 5.5^{\mathrm{e}}$ & $36.2 \pm 7.3^{\mathrm{c}}$ \\
\hline Viable $(\%)$ & $45.2 \pm 8.5 \mathrm{fg}$ & $37.1 \pm 8.3^{\text {h }}$ & $48.0 \pm 10.3$ ef & $53.4 \pm 10.5^{\mathrm{de}}$ & $39.6 \pm 9.0 \mathrm{gh}$ & $59.3 \pm 12.1 \mathrm{dc}$ \\
\hline RR (\%) & 35.1 & 19 & 42.2 & 41.2 & 24.7 & 53.6 \\
\hline
\end{tabular}

Different letters in superscript at the same rowdeminstrate significant different ( $<0.01)$; G (glis erol); EG (etilen glikol dan gliserol); DMF(dimethilformamide); SM (spermatozoa motil); SH (spermatozoa hidup) and $\mathrm{RR}$ (recovery rate)

Tabel 3. Effect of Extender, CPAs and its Combination on the Sperm Movement Evaluate with Sperm Vision

\begin{tabular}{lcccccc}
\hline \multirow{2}{*}{ Parameter } & \multicolumn{3}{c}{ Skim trehalosa } & \multicolumn{3}{c}{ DV trehalosa } \\
\cline { 2 - 7 } & $\mathrm{G}$ & EG\&Gly & DMF & G & EG\&G & DMF \\
\hline Total motil $(\%)$ & $65.0 \pm 7.5 \mathrm{~b}^{\mathrm{c}}$ & $42.0 \pm 13.4^{\text {cd }}$ & $71.6 \pm 11.6^{\mathrm{ab}}$ & $69.5 \pm 3.8^{\mathrm{b}}$ & $47.5 \pm 4.9^{\mathrm{c}}$ & $78.9 \pm 7.6^{\mathrm{a}}$ \\
Progresif $(\%)$ & $28.5 \pm 12.8^{\mathrm{b}}$ & $11.9 \pm 4.3^{\mathrm{d}}$ & $35.1 \pm 14.8^{\mathrm{ab}}$ & $28.5 \pm 3.7^{\mathrm{b}}$ & $19.5 \pm 4.1^{\mathrm{c}}$ & $41.5 \pm 5.5^{\mathrm{a}}$ \\
DAP $(\mu \mathrm{m})$ & $16.2 \pm 4.5$ & $14.8 \pm 2.9$ & $16.1 \pm 1.5$ & $16.5 \pm 4.5$ & $19.1 \pm 2.6$ & $17.6 \pm 0.8$ \\
DCL $(\mu \mathrm{m})$ & $19.9 \pm 11.5$ & $23.5 \pm 5.5$ & $28.2 \pm 3.3$ & $27.2 \pm 10.0$ & $29.6 \pm 5.3$ & $32.3 \pm 2.6$ \\
DSL $(\mu \mathrm{m})$ & $11.7 \pm 2.1$ & $11.2 \pm 2.1$ & $12.0 \pm 0.8$ & $11.3 \pm 1.5$ & $12.6 \pm 1.5$ & $12.5 \pm 0.8$ \\
VAP $(\mu \mathrm{m} / \mathrm{s})$ & $40.4 \pm 9.4$ & $37.9 \pm 8.3$ & $40.1 \pm 3.9$ & $41.8 \pm 11.1$ & $47.9 \pm 7.6$ & $43.0 \pm 2.4$ \\
VCL $(\mu \mathrm{m} / \mathrm{s})$ & $59.9 \pm 14.3$ & $61.0 \pm 15.8$ & $68.9 \pm 9.3$ & $69.3 \pm 19.8$ & $74.1 \pm 14.2$ & $76.9 \pm 7.8$ \\
VSL $(\mu \mathrm{m} / \mathrm{s})$ & $29.8 \pm 4.4$ & $29.13 \pm 6.0$ & $30.3 \pm 2.1$ & $28.7 \pm 3.6$ & $31.9 \pm 4.4$ & $30.4 \pm 2.4$ \\
STR $(\%)$ & $72.0 \pm 0.1$ & $79.0 \pm 0.1$ & $75.0 \pm 0.1$ & $69.0 \pm 0.1$ & $71.0 \pm 0.1$ & $71.0 \pm 0.0$ \\
LIN $(\%)$ & $50.0 \pm 0.1$ & $52.0 \pm 0.1$ & $44.0 \pm 0.1$ & $43.0 \pm 0.1$ & $44.0 \pm 0.0$ & $39.0 \pm 0.0$ \\
WOB $(\%)$ & $66.0 \pm 0.1$ & $66.0 \pm 0.1$ & $58.0 \pm 0.0$ & $61.0 \pm 0.1$ & $66.0 \pm 0.0$ & $54.0 \pm 0.0$ \\
ALH $(\mu \mathrm{m})$ & $3.9 \pm 1.0$ & $4.0 \pm 0.8$ & $4.7 \pm 0.3$ & $4.3 \pm 0.3$ & $4.3 \pm 0.4$ & $5.0 \pm 0.4$ \\
BCF $($ freq) & $17.6 \pm 3.4$ & $17.7 \pm 6.4$ & $17.4 \pm 1.3$ & $17.5 \pm 5.8$ & $19.3 \pm 4.6$ & $17.7 \pm 1.1$ \\
\hline Differyyyyyyyyyyyyyyy
\end{tabular}

Different letters in superscript in the same row demonstrate significant differences $(p<0.05)$ Gly: gliserol, EG: Etilen glykol, DMF : dimethilformamide

DAP: dance average path velocity, DCL: dance curvilinear velocity, DSL: dance straight line, VAP: average path velocity, VCL: curvilinear velocity, VSL: straight line velocity, STR: straightness, LIN: linearity, WO: wobble, ALH: Amplitude Lateral head displacement, BCF: Beat cross frequency 
was added by the cryoprotectant, which conwas $5 \%$ glycerol, ethylene glycol (3\%)-glycerol (3\%) combination or $5 \%$ dimethylformamide (DMF) (Table 1).

Semen was collected using a modified artificial vagina which was made of a Nishikawa type artificial vagina (Japan) with a Missouri type semen collecting tube (Nasco, Fort Atkinson, WI); the mouth opening of the collecting tube was covered by gauze to strain out the gel fraction of the ejaculates. Macroscopic evaluation on semen samples included volume ( $\mathrm{ml})$, color, consistency, and $\mathrm{pH}$ ( $\mathrm{pH}$-special indicator paper; Merck, interval 6-8, scale 0.2). Microscopic evaluation on semen samples included percentages of motile sperm and viable sperm, sperm concentration, and sperm morphology. Sperm concentration was measured using a Neubauer chamber; semen was diluted 1: 100 in 3\% NaCl. Sperm morphology was evaluated on semen smears on glass slides stained with Williams. The good quality semen was equally divided into 6 tubes; skim milk-based centrifugation extender was added 1:1 into the first three tubes; DV centrifugation extender was added into the remaining three tubes. Extended semen in all tubes was then centrifugated for 15 minutes at $1006 \mathrm{x} \mathrm{g}$; supernatant was discarded, and the pellet was added by the cryoprotectants, with the final sperm concentration was $200 \times 10^{6} \%$ $\mathrm{ml}$. The pellet of three semen samples extended with skim milk was added by trehalose-glycerol (STGly), trehalose-ethylene glycol-gylcerol (STEG+Gly), or trehalose DMF (STDMF). Similarly, the pellet of three semen samples extended with DV was then added with trehaloseglycerol (DVTGly), trehalose-ethylene glycolgylcerol (DVTEG+Gly), or trehalose DMF (DVTDMF). Semen samples were individually packed in $0.3 \mathrm{ml} \mathrm{Minitub} \mathrm{straws,} \mathrm{which} \mathrm{then}$ arranged in cassettes, equilibrated for two hours at $4-5^{\circ} \mathrm{C}$ (Arifiantini et al., 2007), and frozen in liquid nitrogen vapor $(4 \mathrm{~cm}$ above the nitrogen level) for 10 minutes before being stored in liquid nitrogen container for 24 hours. Straws were thawed in a $37{ }^{\circ} \mathrm{C}$ water bath for 30 seconds. Motile sperm and viable sperm were evaluated subjectively (quantitatively) on raw semen, and after dilution, after equilibration, and after thawing. As comparison, the quality of thawed semen was evaluated with Spermvision (Minitüb, Tiefenbach, Germany) at Center of Artificial Insemination in Ungaran, Central Java, Indonesia.

Data were analysed as a $2 \times 3$ factorial analysis by random assignments of groups. Each of the two experiments had four replications. When significant differences among treatment were identified, comparisons between means were assessed using Duncan's Multiple Range Test (Walpole, 1982).

\section{RESULTS and DISCUSSION}

\section{Effects of Extender on the Quality of Frozen Semen}

There were no significant different $(\mathrm{p}>0.05)$ on the percentages of motile and viable sperm in skim milk trehalose $(21.7 \%$ and $43.4 \%$, respectively) compare with those extended with DV trehalose extender $(26.9 \%$ and $50.8 \%$, respectively)

\section{Effects of the Cryoprotectants on the Quality of Frozen Semen}

Subjective evaluation demonstrated that DMF demonstrated highest percentages of motile and viable sperm $(40.5 \%$ and $67.8 \%$

Tabel 4. Mean ( \pm S.E.M.) After Thawing Quality Evaluate Subjective versus CASA

\begin{tabular}{cccccc}
\hline \multirow{2}{*}{$\begin{array}{c}\text { Extender } \\
\text { Cryoprotective } \\
\text { agent }\end{array}$} & \multicolumn{2}{c}{ CASA } & \multicolumn{2}{c}{ Subjective } \\
\cline { 3 - 6 } & & Total motile & Progressive & Progressive & Viable \\
& Gly & $65.0 \pm 7.5$ & $28.5 \pm 12.8$ & $27.4 \pm 3.4$ & $48.4 \pm 5.1$ \\
Skim Trehalose & EG+Gly & $42.0 \pm 13.4$ & $11.9 \pm 4.3$ & $15.5 \pm 3.1$ & $39.7 \pm 6.7$ \\
& DMF & $71.6 \pm 11.6$ & $36.2 \pm 14.8$ & $31.7 \pm 2.9$ & $52.5 \pm 6.3$ \\
\hline DV Trehalose & Gly & $69.5 \pm 3.8$ & $28.5 \pm 3.7$ & $31.0 \pm 3.0$ & $56.4 \pm 7.2$ \\
& EG+Gly & $47.5 \pm 4.9$ & $19.5 \pm 4.1$ & $19.1 \pm 3.8$ & $39.8 \pm 7.3$ \\
& DMF & $78.9 \pm 7.6$ & $41.5 \pm 5.5$ & $40.2 \pm 4.0$ & $64.8 \pm 7.0$ \\
\hline
\end{tabular}

ST : Skim rehalosa ; DVT : DV trehalosa; Gly: glycerol; EG :etilen glykol ; DMF : dimethilformamide; Data from 2 stallion 
respectively); followed by glycerol (31.5\% and $56.8 \%$, respectively), and combination of ethylene glycol-glycerol (19.3\% and 40.1\%, respectively). This result compromise with those conducted by CASA, DMF had the highest percentages of total motile sperm (74.3\%) with progressive motility $37.8 \%$ ), followed by glycerol $(67.2 \%$ and $28.5 \%$, respectively) and the lowest of total motile sperm and progressive motile was ethylene glycolglycerol (44.1\% and $14.8 \%$, respectively).

\section{Effects of Cryoprotectant and Extender on the Quality of Frozen Semen}

Subjective evaluation demonstrated that semen extended with DVTDMF demonstrated post-thaw motility (36.2\%), higher than those extended with STDMF (28.5\%), DVTG (27.8\%), STG $(26.7 \%)$, DVTEG+Gly $(16.7 \%)$ or STEG+Gly witch only $12.8 \%$ (Table 2 )

Evaluation using CASA aggreement with the subjective evaluation; semen extended with DVTDMF had the highest percentage of progressive motility $(41.5 \%)$, followed by those extended with STDMF (35.1\%), STG $(28.5 \%)$, or DVTG (28.5\%) (Table 3). Semen extended with STEG+Gly had the lowest percentages of total motile sperm and sperm with progressive motility which were $42.0 \%$ and $11.9 \%$, respectively.

Studies using Sperm Vision on the evaluation of stallion sperm were limited; some studies using CASA system reported that sperm with rapid average path were those having $>30$ $\mu \mathrm{m} / \mathrm{s}$ curvilinear velocity (VCL). The mean of VCL in this study was $68.4>30 \mu \mathrm{m} / \mathrm{s}$; the sperm had rapid velocity in all entender groups.

The mean percentage of sperm with progressive motility using CASA system was different by $1-2 \%$ than subjective evaluation; exception was in STEG or STDMF, whereas the difference was $4-5 \%$ (Table 4). This fact suggested that the evaluator's skill and experience were important on the subjective assessment of sperm motility.

Cryoprotectants can be classified by their role in cryopreservation into two main groups, namely penetrating agents, which maintain intracellular and extracellular solute concentration, and non-penetrating agents, which maintain only extracellular solute concentration (Woelders et al., 1997). Based on the main component, cryoprotectants can be classified into alcohol groups (ethylene glycol, glycerol, etc.) and amides (dimethylformamide, acetamide, methylformamide, etc.) (Alvarenga et al., 2005).
The mechanism of work, type, and concentration are the main three factors which influence the quality of cryoprotectants to protect sperm during cryopreservation. Cryoprotectants prevent icecrystals forming; however, they are toxic to sperm during equilibration and post-thawing. Stallion sperm are known to be fragile; the right semen extender and cryoprotectant are certainly needed.

In this study, DMF in ST or DVT demonstrated a better protection on sperm during freezing than glycerol or ethylene glycol-glycerol. This result was different from what was reported by Squires et al. (2004), whereas $0.5 \mathrm{M}$ glycerol had a higher percentage of motile sperm (61\%) than those with methylformamide $(40 \%)$ and dimethylformamide (38\%). The percentage of motile sperm was increased to $48-54 \%$ when higher concentration of MF and DMF ( $0.6 \mathrm{M}$ or $0.9 \mathrm{M})$ was used; this was similar to glycerol $(52 \%)$. The results of this study suggest that DMF had the best protection on stallion sperm during cryopreservation; this was in agreement with some previous studies (Alvarenga et al., (2004); Medeiros et al. (2002); Vidament et al., 2002).

The choice of cryoprotectants is based on their ability to protect sperm during freezing, and their low molecular weight, which is important in reducing the high osmolarity-induced sperm toxicity by faster and easier cellular penetration. The molecular weights of ethylene glycol, DMF, and glycerol were 62.07; 73, and 92.10, respectively.

The osmotic pressures of STEG+Gly, STDMF, DVTG, DVTEG+Gly, and DVTDMF were $1089 ; 1317 ; 1234 ; 1380 ; 1392$ and 1158 mosm $/ \mathrm{kg}$, respectively. According to Meyers et al. (2004), the volume of stallion sperm is 24.4 $\mu \mathrm{m}^{3}$, with the tolerance on extender osmolarity varies from 150 to $900 \mathrm{mosm} / \mathrm{kg}$, based on these, semen extenders with osmotic pressure close to $900 \mathrm{mOsm} / \mathrm{kg}$ are STG and DVTDMF. In facts, semen extended with skim trehalose-glycerol had lower post-thawing motility than semen diluted with other extenders which have higher osmotic pressure. It is assumed that the extender's osmotic pressure, main component of extender, and cryoprotectant's toxicity influence the quality of frozen semen post-thawing.

DV extender combined with cryoprotectants appeared to protect the sperm better during freezing than skim milk extender, which was combined with the same cryoprotectants; this is due to the perfect components of DV extender, 
sodium buffer lechitin and lipoprotein from egg yolk. The lipid component of semen extender maintains the integrity of phospholipid bilayer of the cell membrane and protects sperm from cold shock (Parks and Graham, 1992). It is believed that Equex STM (Orvus es paste) is able to store more lipids from egg yolk in semen extender. In addition, DV extender contains EDTA which is a calcium chelating agent (Crabo, 2001).

Previous studies demonstrated that different types and concentrations of cryoprotectants and different breeds of the stallion had different results; the type and concentration of cryoprotectants are carefully selected for every semen samples prior to freezing. In this study, DVTDMF was the best semen extendercryoprotectant combination, followed by DVT glycerol and SMTDMF. It was concluded that dimethylformamide was the best cryoprotectant of the stallion semen in this study.

Stallion sperm have a low tolerance to cold shock; this appears correlated to differences in the phospholipid composition on their plasma membrane. The arachidonic acid (unsaturated fatty acid) in stallion sperm is higher (18.2\%) than in bull (3.5\%) and ram (4.5-5\%) sperm (Chow et al., 1986; White, 1993). The inverse proportion of docosapentaenoic acid (DPA; 22:5) and docosahexaenoic acid (DHA; 22:6) on phosphatidylcholine and phosphatidylethanolamine may responsible to the sensitivity of stallion spermatozoa to damage during cryopreservation (Gadella et al., 2001). White (1993) reported that DPA in bull sperm is very low; while in stallion sperm it reached $17.2 \%$. In contrast, Chow et al. (1986) reported that the DHA was as high as $61.3 \%$ and $61.4 \%$ in bull and ram sperm, respectively; while it was $7.6 \%$ in stallion sperm.

For most substances, melting and freezing points are approximately equal (Brown and Brown, 2000). The melting points of DHA, DPA and arachidonic acid are $-44^{\circ} \mathrm{C},-54^{\circ} \mathrm{C}$ and $-49^{\circ} \mathrm{C}$, respectively (VanderJagt et al., 2003). The high DPA and arachidonic acid concentration on stallion sperm plasma membrane with their low melting points are believed contributing to the speed differences between extra- and intra-cellular freezings. The high freezing point of the fatty acid on stallion sperm plasma membrane causes lower tolerance to cellular damage than bull or rams sperm. Bull, ram, and stallion sperm have differences in osmotic water permeabilities, which are $10.5-10.8 \mu \mathrm{m} \mathrm{min}^{-1} \mathrm{~atm}^{-1}, 8.47 \mu \mathrm{m} \mathrm{min}^{-1} \mathrm{~atm}^{-}$ 1 , and 26,0 $\mu \mathrm{m} \mathrm{min}^{-1} \mathrm{~atm}^{-1}$, respectively (Noiles et al., 1993). The lower melting point of plasma membrane along with the rapid movement of water from inside the cell during stallion sperm freezing, the faster extracellular freezing; this causes water to move out from inside sperm to the extracellular environment, and sperm become progressively dehydrated.

\section{CONCLUSION}

In this study, DMF demonstrated a better protection to the sperm during semen freezing than glycerol or glycerol-ethylene glycol combination and DV extender combined with DMF had the best results than other semen extender-cryoprotectant combination groups.

\section{ACKNOWLEDGEMENT}

Thanks to the Athena Stable owners and keeper for supplying the equine semen and Bondan Achmadi for technical help.

\section{REFERENCES}

Aisen, E.G., H.L Alvarez, A. Venturino and J.J. Garde. 2000. Effect trehalose and EDTA on cryoprotective action of ram semen diluents. Theriogenology 53: 1053-1061.

Arifiantini, R. I., I. Supriatna, Samsulrizal. 2007. Determination of equilibration time during semen processes in stallion using skim milk extender. J. Anim. Prod. 9(3):145-152

Alvarenga, M.A., K.M. Leão, F.O. Papa, F.C. Landim-Alvarenga, A.S.L Medeiros and G.M. Gomes. 2004. The use of alternative cryoprotectors for freezing stallion semen. Proceedings of a Workshop on transporting Gametes and Embryos, 2 ${ }^{\text {nd }}-5$ th October, 2003 Brewster, Massachusetts: R \& W Publications.

Alvarenga, M.A, F.O. Papa, F.C. LandimAlvarenga, A.S.L. Medeiros. 2005. Amides as cryoprotectants for freezing stallion semen. A. Review. Anim. Reprod. Sci. 89 : 105-113.

Berndtson, W.E. and R.H. Foote. 1972. Bovine sperm cell volume at various intervals after addition of glycerol at $5{ }^{\circ} \mathrm{C}$. Cryobiology 9 : 29-33

Chow, P.Y.W., I.G. White and B.W. Pickett. 1986. 
Stallion sperm and seminal plasma phospholipids and glycerylphosphorylcholine. Anim. Reprod. Sci. 11: 207-213.

Crabo, B.G. 2001. Physiological aspects of stallion semen cryopreservation. AAEP Proceeding Vol. 47: 291-294.

Gadella, B.M., R. Rathi, J.F.H.M. Brouwers, T.A.E. Stout and B. Colenbrander. 2001. Capacitation and the acrosome reaction in equine sperm. Anim. Reprod. Sci. 68: 249265.

Gao, D.Y., J. Liu, C. Liu, L.E. McGann, P.F. Watson and F.W. Kleinhaus.1995. Prevention of osmotic injury to human spermatozoa during addition and removal of glycerol. Hum. Reprod. 10:1109-22.

Ijaz, A and R. Durcarme. 1995. Effect of various extender and taurine on survival of stallion sperm cooled at $5^{\circ} \mathrm{C}$. Theriogenology 44 : 1039-1050.

Kenney, R.M., R.V. Bergman, W.L. Cooper and G.W. Morse. 1975. Minimal contamination techniques for breeding mares: Technique and preliminary findings. Proc. Am. Assoc. Equine Practnr: 327-336.

Meyers, S.A., F. Tablin and J.H. Crowe. 2004. Does Cellular Injury Resulting From Cryopreservation Share Traits With Sperm Capacitation? Proceedings of a Workshop on transporting Gametes And Embryos $2^{\text {nd }}$ 5th October 2003 Brewster, Massachusetts : $\mathrm{R} \&$ W Publications

Nash, T. 1996. Chemical constitution and physical properties of compounds able to protect living cells against damage due to freezing and thawing. In: Meryman HT, editor. Cryobiology. New York: Academic Press. pp 179-210.

Park J.E. and J.K. Graham 1992. Effects of cryopreservation procedures on sperm membranes. Theriogenology $38: 209-222$.

Rudolph, A.S. and J.W. Crowe. 1985. Membrane stabilization during freezing: the role of two natural cryoprotectants, trehalose and praline. Cryobiology 22: 367-377

Squires, E.L, S.L. Keith and J.K. Graham. 2004. Evaluation of alternative cryoprotectants for preserving stallion sperm. Theriogenology 62: 1056-1065.

VanderJagt, D.J., M.R. Trujillo, F.D. Thomas, Y.S. Huang, L.T. Chuang and R.H. Glew. 2003. Phase angle correlates withn-3 fatty acids and cholesterol in red cells of Nigerian children with sickle cell disease. Lipids Health Dis.; 2: 2. Published online 2003 May 6. Doi: 10.1186/1476-511X-2-2.

Vidament, M., C. Daire, J.M. Yvon, P. Doligez, B. Bruneau, M. Magistrini and P. Ecot. 2002. Motility and fertility of stallion semen frozen with glycerol and /or dimethyl formamide. Theriogenology. 58: 249-251.

Walpole RE. 1982. Introduction to Statistics $3^{\text {rd }}$ ed. London. Macmillan,

White, I.G. 1993. Lipids and calcium uptake of sperm in relation to cold shock and preservation: a Review. Reprod. Fertil. Dev. 5: 639-658

Woelders, H., A. Mathiijs and B. Engel. 1997. Effects of trehalose, and sucrose, osmolality of the freezing medium and cooling rate on viability and intactness of bull sperm after freezing and thawing. Cryobiology 35: 93105. 